Brit. Heart J., 1965, 27, 365.

\title{
THE TRANSMISSION OF ELECTRICAL FORCES FROM THE HEART TO THE BODY SURFACE
}

\author{
BY \\ JOHN HAMER, DENNIS BOYLE, AND EDGAR SOWTON \\ From The Institute of Cardiology and The National Heart Hospital, London W.I
}

Received September 10, 1964

The changes in electrical potential at the surface of the body that are recorded as the electrocardiogram are the result of changes in the electrical currents produced by the myocardium. These currents are due to variations in the transmembrane potentials of the muscle fibres during each cardiac cycle. The uneven electrical properties of the tissues in the thorax distort the cardiac electrical forces before they reach the body surface, and these changes must be taken into consideration in the interpretation of the electrocardiogram.

The introduction of the bipolar electrode catheter for pacing patients with heart block has provided a known source of electrical activity within the heart which can be compared to the natural myocardial forces. The surface potentials produced by stimuli applied to the bipolar catheter electrode in the right ventricle give an indication of the distortion of the electrical pattern that occurs during transmission of cardiac electrical activity to the body surface. The information obtained in this way is of value in the assessment of the underlying concepts of electrocardiography and vectorcardiography.

\section{SubJECTS AND MeTHODS}

Five patients with bipolar electrode catheters in the right ventricle were studied. Complete heart block was present in each subject. The solid catheter* was introduced through a peripheral vein and the tip impacted in the trabeculæ at the apex of the right ventricle under fluoroscopic control. The catheter electrodes consist of a platinum tip $2 \mathrm{~mm}$. long and a platinum ring $2 \mathrm{~mm}$. in width, $1 \mathrm{~cm}$. from the tip. The position and orientation of the electrodes were estimated from grid postero-anterior and lateral $\mathrm{x}$-ray films at a tube distance of $40 \mathrm{in}$. (101 cm.) and $48 \mathrm{in}$. (122 cm.), respectively, with skin markers on the mid-clavicular line anteriorly and in the mid axilla. Repeated radiographs showed no evidence of change in position of the catheter tip. The lowest possible potentials (between 1.7 and 3 volts) needed to maintain pacing were applied to the catheter tip electrodes, in 2 cases with the tip electrode negative and in 4 with the tip electrode positive. A Devices pacemaker giving biphasic impulses lasting $2 \mathrm{msec}$. was used (Sowton and Davies, 1964) $\dagger$. The initial larger deflection was measured at the body surface by means of a Cambridge photographic recording apparatus with an input impedance of 5 mega ohms and a uniform frequency response up to $100 \mathrm{cps}$, using conventional $\mathrm{V}$ leads and a recording speed of $100 \mathrm{~mm}$./sec. (Fig. 1). The input impedance of the limb electrodes used for the Wilson terminal was high $(100 \mathrm{k}$. ohms) to minimize the effect of variations in skin resistance. Electrode jelly was firmly applied at each electrode site. Records were obtained from 12

* U.S. Catheter Corporation, type C51, Glenns Falls, N.Y.

$\dagger$ As the frequency response of the recording apparatus is limited, the square wave stimulus applied to the bipolar catheter electrode is recorded as a spike deflection. However, the consequent proportionate reduction in the maximum recorded deflection will be similar at all parts of the body surface. 


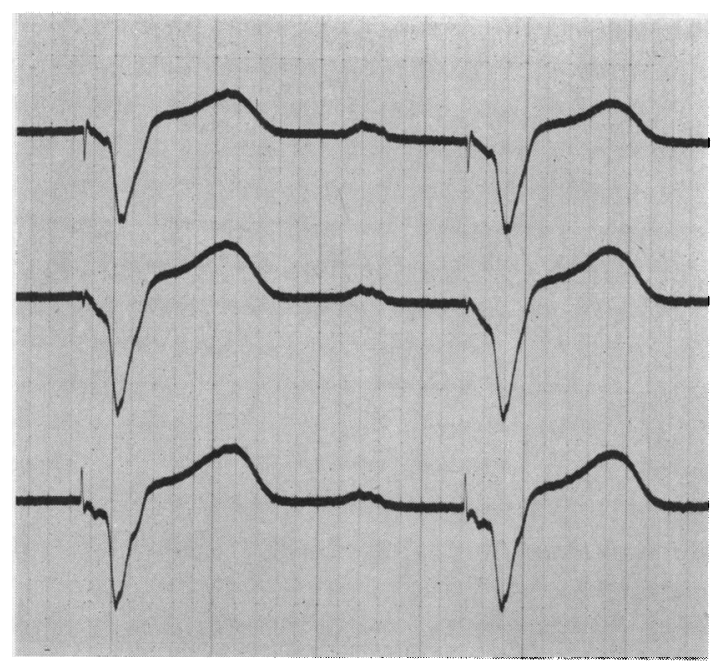

FIG. 1.-Electrocardiogram during pacing. Simultaneous standard leads, showing the diphasic stimulus followed by the resulting QRS-T complex. positions round the chest at 5 or 6 levels 3 in. $(7.5 \mathrm{~cm}$.) apart, and in some cases at additional intermediate points. A conventional 12-lead electrocardiogram and the xyz leads of the cube system (Grishman, Borun, and Jaffe, 1951) were also recorded.

Surface isopotential maps were constructed and the horizontal level of the electrode determined from the maximal positive and negative skin potentials. The cross-section of the thorax at this level was considered as a circle with the 12 electrode positions spaced at equal distances on the circumference. The apparent position of the dipole was estimated as the junction of a line joining the points of zero potential, and either a line joining the maximal and minimal points or the radius to the point on the surface where the potential was changing most rapidly (Nelson, 1957). The orientation of the electrode was taken as the direction of the line joining the maximal and minimal surface potentials.

The orientation of the catheter tip was also determined from the xyz leads of the cube system and from the conventional electrocardiogram, using the standard limb leads for the frontal axis (Einthoven, Fahr, and de Waart, 1913) and a tetrahedral reference system using lead V1 (Burger, van Milaan, and den Boer, 1952; Goldberger, 1953) to give the spatial direction.

The apparent conductivity of the tissues was obtained from the formula $\mathrm{V}=\left(2+\frac{c}{r}\right) K \cos \omega c^{-2}$, where $K=\frac{3 \rho}{4 \pi} M$ (Nelson, 1961), $r$ is the radius of the thorax section, $c$ the distance between the catheter electrode and the surface electrode, $V$ the surface potential, and $\omega$ the angle between the catheter and the surface electrode. As the electrical moment $(M)$ of the stimulus applied to the catheter tip (current $\times$ interelectrode distance) and the geometric constant $\frac{3}{4 \pi}$ do not change, any variation in $\frac{3 \rho}{4 \pi} M$ must be due to changes in tissue resistivity $(\rho)^{*}$. Values were calculated for the predicted and the radiological positions of the catheter tip. Estimates based on surface potentials less than $0.1 \mathrm{mV}$ or angles of more than $80^{\circ}$ were omitted because of the large errors of measurement under these circumstances.

\section{RESULTS}

The surface potential maps showed single maximum and minimum points in 3 out of 5 patients. In 2 subjects (Be. and Ro.), however, islands of paradoxical potential were found to the right of the mid-line anteriorly. In one of these subjects a second study (Ro'.) with the catheter tip in a slightly different position showed no distortion of the surface field (Fig. 2).

In Table I and Fig. 3, the radiological position of the catheter tip is compared to the position predicted from the surface potential map. The horizontal level of the catheter tip was generally close to that predicted. The simple method of estimation of electrode position from the maximum and minimum potentials on the body surface and the line of zero potential gave a reasonable prediction of the relation of the electrode to the surface of the body, but the values were closer to the mid-line than the true position of the electrode. The method of Nelson (1957), using the radius to the point on the body surface where the potential was changing most rapidly, also gave values too

* The properties of the tissues described as "resistive" in fact contain reactive components, but as these are predominantly capacitive rather than inductive (Davis and Sowton, 1964) no undue effect on electrical changes at high frequency is to be expected. 
TABLE I

LOCATION OF CATHETER TIP

\begin{tabular}{|c|c|c|c|c|c|c|c|c|c|}
\hline \multirow{2}{*}{\multicolumn{2}{|c|}{ Patient }} & \multicolumn{2}{|c|}{$\begin{array}{c}\text { Level } \\
\text { (cm. below sternal } \\
\text { angle) }\end{array}$} & \multicolumn{3}{|c|}{$\begin{array}{c}\text { Angle }\left({ }^{\circ}\right) \\
\text { in horizontal section }\end{array}$} & \multicolumn{3}{|c|}{$\begin{array}{l}\text { Depth as } \% \text { from centre in } \\
\text { horizontal section }\end{array}$} \\
\hline & & $\begin{array}{l}\text { Radio- } \\
\text { graph }\end{array}$ & $\begin{array}{l}\text { Surface } \\
\text { map }\end{array}$ & Radiograph & $\begin{array}{l}\text { Apparent } \\
\text { (from } \\
\text { surface } \\
\text { map) }\end{array}$ & $\begin{array}{l}\text { Nelson } \\
\text { method }\end{array}$ & Radiograph & $\begin{array}{l}\text { Apparent } \\
\text { (from } \\
\text { surface } \\
\text { map) }\end{array}$ & $\begin{array}{l}\text { Nelson } \\
\text { method }\end{array}$ \\
\hline $\begin{array}{l}\text { Br. } \\
\text { Be.* } \\
\text { Bu. } \\
\text { Ne. } \\
\text { Ro.*' } \\
\text { Ro.' } \\
\text { Mean }\end{array}$ & $\begin{array}{l}. \\
\cdots \\
. \cdot\end{array}$ & $\begin{array}{r}13 \\
11 \\
8 \\
13 \\
13 \\
13 \\
12\end{array}$ & $\begin{array}{r}5 \\
8 \\
8 \\
10 \\
13 \\
8 \\
9\end{array}$ & $\begin{array}{l}61 \\
48 \\
46 \\
\frac{70}{65}+ \\
58\end{array}$ & $\begin{array}{l}85 \\
95 \\
93 \\
80 \\
53 \\
81 \\
81\end{array}$ & $\begin{array}{r}86 \\
100 \\
57 \\
73 \\
72 \\
74 \\
77\end{array}$ & $\begin{array}{l}89 \\
66 \\
72 \\
\frac{76}{58}+ \\
72\end{array}$ & $\begin{array}{l}98 \\
81 \\
65 \\
90 \\
40 \\
44 \\
70\end{array}$ & $\begin{array}{r}100 \\
48 \\
16 \\
35 \\
56 \\
40 \\
49\end{array}$ \\
\hline
\end{tabular}

* Complex surface map.

$\dagger$ No lateral radiograph.

close to the mid-line, but with this method the predicted position tended to be too near the centre of the thorax (Fig. 3). In Br. the electrode was closer to the body surface than in the other patients, and this position was exaggerated in the estimates made from surface potentials.

The orientation of the catheter tip electrodes predicted from the surface potential map (Nelson, 1957) and from the conventional electrocardiogram or the cube system xyz leads is compared to the radiological findings in Table II. For the frontal plane agreement is good except in the case of Be., where the surface map was complex. In the horizontal plane much greater discrepancies were found. In general, the predictions from the surface maps were no better than from the conventional lead systems.

The apparent resistivity of the body tissues is indicated in Fig. 4. Even when allowance was made for the differences in the applied stimulus there was much individual variation in the size of the surface potentials. However, there was also considerable variation in the apparent resistivity in different parts of the thorax. Larger values, indicating greater resistivity, were consistently found in

TABLE II

Orientation of the Catheter Tip

\begin{tabular}{|c|c|c|c|c|c|c|c|c|c|}
\hline \multirow{2}{*}{\multicolumn{2}{|c|}{ Patient }} & \multicolumn{4}{|c|}{ Frontal plane $\left({ }^{\circ}\right)$} & \multicolumn{4}{|c|}{ Horizontal plane $\left({ }^{\circ}\right)$} \\
\hline & & $\begin{array}{c}\text { X-ray } \\
\text { position }\end{array}$ & $\begin{array}{l}\text { Triaxial } \\
\text { system }\end{array}$ & $\begin{array}{l}\text { Cube } \\
\text { system }\end{array}$ & $\begin{array}{l}\text { Surface } \\
\text { map }\end{array}$ & $\begin{array}{c}\text { X-ray } \\
\text { position }\end{array}$ & $\begin{array}{c}\text { Tetrahedral } \\
\text { system }\end{array}$ & $\begin{array}{l}\text { Cube } \\
\text { system }\end{array}$ & $\begin{array}{c}\text { Surface } \\
\text { map }\end{array}$ \\
\hline $\begin{array}{l}\text { Br... } \\
\text { Be** } \\
\text { Bu. } \\
\text { Ne. } \\
\text { Ro.* } \\
\text { Ro'. }\end{array}$ & $\begin{array}{l}\ldots \\
\cdots \\
\cdots \\
\cdots \\
\cdots\end{array}$ & $\begin{array}{r}-40 \\
-15 \\
-30 \\
0 \\
10 \\
0\end{array}$ & $\begin{array}{r}-40 \\
30 \\
-10 \\
0 \\
5 \\
-\end{array}$ & $\begin{array}{r}-65 \\
45 \\
-25 \\
0 \\
-5 \\
0\end{array}$ & $\begin{array}{r}-50 \\
40 \\
-15 \\
5 \\
30 \\
20\end{array}$ & $\begin{array}{r}-20 \\
50 \\
25 \\
15 \\
-40\end{array}$ & $\begin{array}{c}-40 \\
-70 \\
-15 \\
-50 \\
-75 \\
-\end{array}$ & $\begin{array}{r}-30 \\
-0 \\
-20 \\
-5 \\
5\end{array}$ & $\begin{array}{r}-60 \\
-5 \\
55 \\
-5 \\
10 \\
45\end{array}$ \\
\hline \multicolumn{2}{|c|}{$\begin{array}{l}\text { Average error } \\
\text { Range } \quad .\end{array}$} & & +45 to -5 & +60 to -25 & $\begin{array}{c}+18 \\
+55 \text { to }-10\end{array}$ & & -20 to -120 & -10 to -35 & $\begin{array}{l}-16 \\
+30 \text { to }-55\end{array}$ \\
\hline
\end{tabular}

$\mathrm{Br}$. and Be. corrected for reversed polarity of catheter tip.

* Complex surface patterns. 


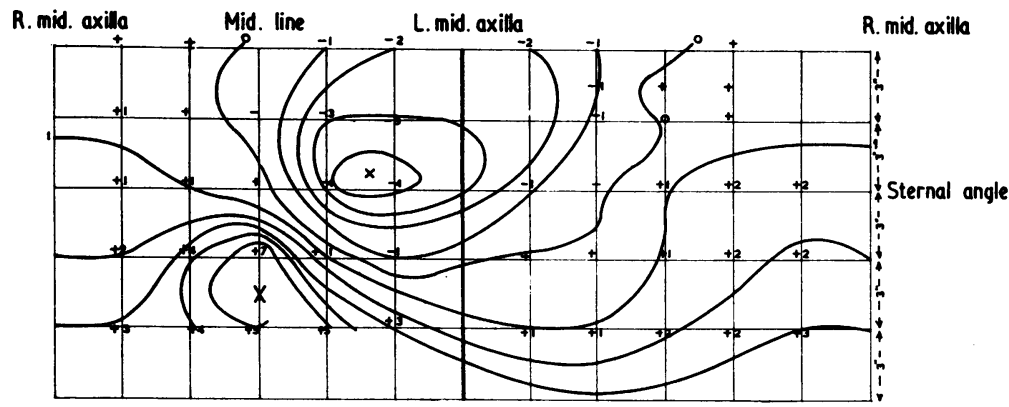

Br.

FRONT

$\underline{B A C K}$

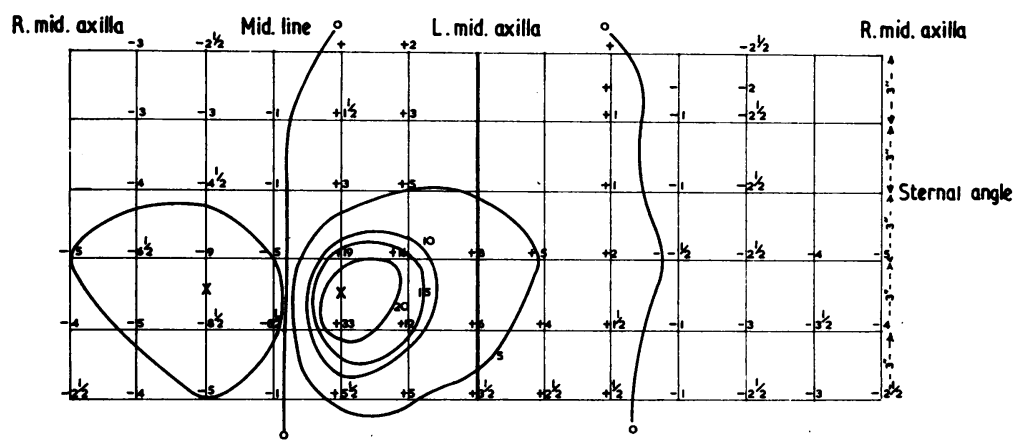

Ne.

FRONT BACK

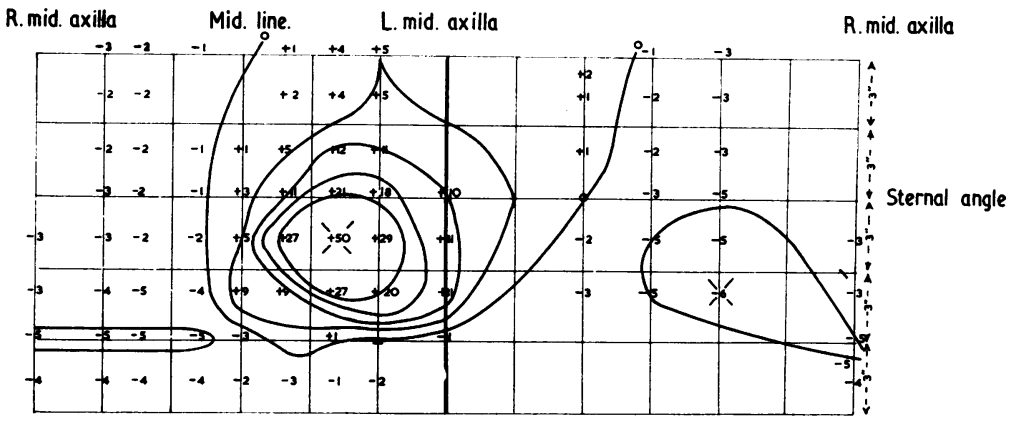

Bu.

FIG. 2.-Surface potentials produced by a stimulus applied to a bipolar electrode in the right ventricle. $\mathrm{Br}$., Ne., and $\mathrm{Bu}$. (above) show single maximum and minimum points with an even intervening field. Be. and Ro. (opposite) show complex patterns with anomalous regions of positive or negative potential on the right anterior chest wall. A later study in one of these patients (Ro') with the stimulating electrode in a different position shows no distortion of the surface field. These findings indicate that variations in the electrical properties of the thoracic tissues can produce complex surface potential patterns from a simple bipolar stimulus within the heart. 

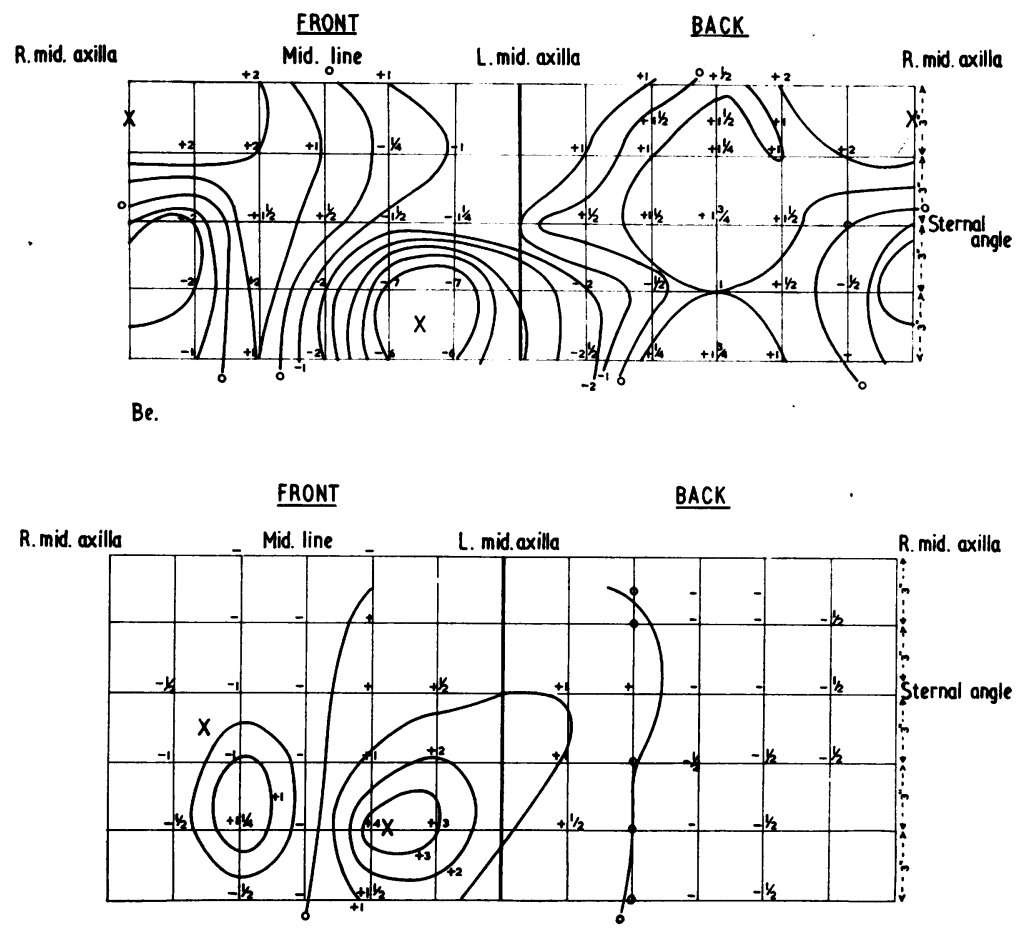

Air.

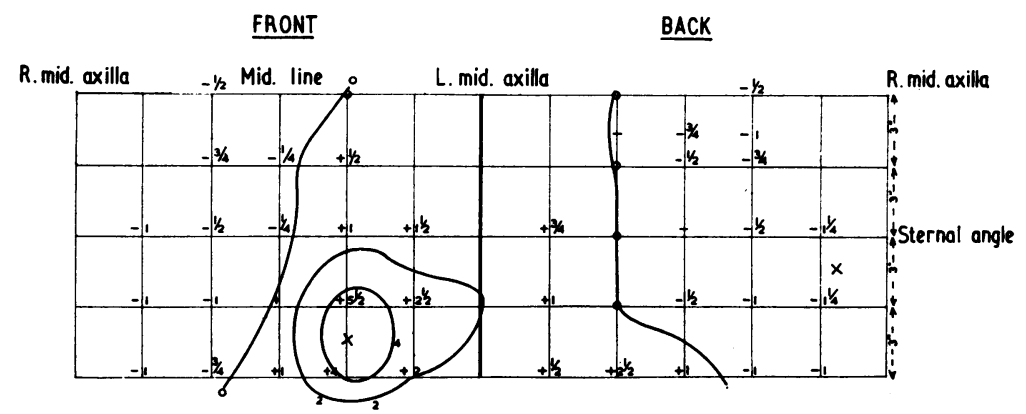

Ro!

FIG. 2

the left anterior chest. These variations were somewhat reduced when the calculation was made on the basis of the radiological estimate of the position of the catheter tip.

\section{Discussion}

The heart is a source of electric current placed within the chest and producing changes on the surface of the body, which are recorded as the electrocardiogram. We are here concerned with the relation between these surface electrical changes and the events within the heart which produce them. An early suggestion (Einthoven et al., 1913) that the heart might be regarded as a single dipolar source of electrical activity has been supported by much experimental work (Craib and Canfield, 1927; Frank, 1955a), but there is increasing evidence that this hypothesis is only approximately correct (Wilson and his colleagues, 1944; Nelson, 1957; Taccardi, 1963).

Variations in the electrical properties of the thoracic tissues must affect the surface field produced by the cardiac electrical activity. Recent work (Schwan and Kay, 1957; Rush, Abildskov, and 

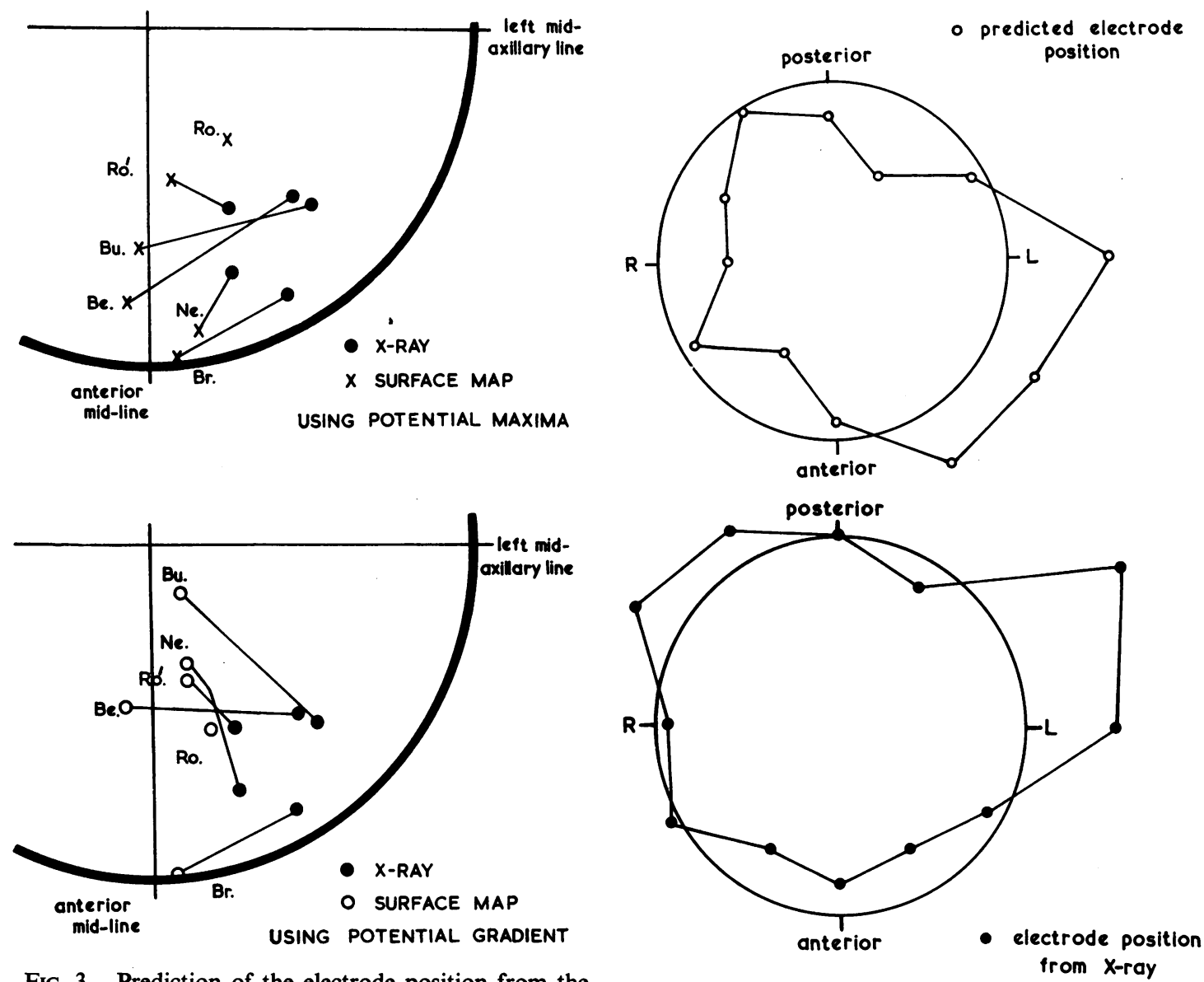

FIG. 3.-Prediction of the electrode position from the surface potential map. The predicted position of the catheter tip electrode is compared to the position shown on the radiograph. The electrode was assumed to be on the line joining the surface points of zero potential and either (above) a line joining the points of maximum and minimum potential, or (below) the radius to the point on the surface where the potential was changing most rapidly (i.e. the point of maximum potential gradient).

FIG. 4.-Variations of the apparent resistivity of the tissues in a cross-section of the thorax. Mean values from 5 subjects derived from surface potentials using the formula of Nelson (1961) (see text). Above: from predicted electrode position (by potential gradient method). Below: from position of electrode on the radiograph. The apparent increase in resistivity in the left anterior chest shown on the upper diagram is probably an effect of the high conductivity of the blood in the ventricular cavities. The distortion is less when calculation is based on the x-ray position of the catheter tip.

McFee, 1963) shows relatively little variation between tissues such as lung, liver, and muscle, but the electrical resistivity of blood is approximately one-tenth of that of other tissues. It seems likely that the low resistivity of the blood in the cardiac chambers increases the tendency of the heart to behave as a single dipole (Brody, 1956). Although lung contains a large proportion of air, its resistivity is not as high as might be expected, probably because of the large amount of blood present.

A further difficulty in the interpretation of surface electrical potentials is the increase in potential produced by the boundary between the body tissues and the surrounding air (Nelson, 1955; Frank, 1957). Many attempts have been made to compare the potentials produced at the surface of thorax 
models with the natural electrocardiogram, but in much of this work the effects of inhomogeneity of the medium or boundary phenomena were neglected. Nelson (1961) developed a simple mathematical expression for the potential at the surface of a sphere due to an eccentric dipole which takes into consideration boundary effects, and this expression has been used in the present work.

In vectorcardiography and orthogonal lead systems of electrocardiography the heart is assumed to behave as a single dipolar source, and lead systems are arranged to obtain relatively pure vertical (x), horizontal (y), and sagittal (z) components. The effect of variations in the position of the dipole can be reduced by using special lead systems (Frank, 1957). Clearly any variation in the effective axes of the leads used (Burger and van Milaan, 1946, 1947, 1948; McFee and Johnston, 1953, 1954a, b; Schmitt, 1957) or a departure from dipolar behaviour will lead to errors in these systems of recording the electrical activity of the heart.

In the present work an attempt has been made to test these assumptions by measuring the surface fields produced from a bipolar electrode introduced into the right ventricular cavity for therapeutic purposes. Similar studies have been performed in the past using œsophageal electrodes (Frank, 1955b), electrodes placed in the hearts of dogs (Horan, Flowers, and Brady, 1963) or in the human post mortem (Burch, Cronvich, and Zao, 1961). The only previous attempt to introduce a stimulating electrode into the heart of a living human subject for this purpose was by Butterworth and Thorpe (1951) who passed an insulated bipolar catheter into the right atrium and in one patient studied the changes in the limb lead electrocardiogram when a voltage was applied to the bipolar catheter tip.

In the present work, the catheter tip was inserted in the right ventricle in contact with the endocardium. Examination of the surface maps of potential distribution produced by stimulation of this bipolar electrode shows clear evidence of more than one maximum and minimum in 2 of the 5 patients studied. Similar changes in surface potential maps from the natural QRS complex have been noted by Nelson (1957) and Taccardi (1963) and are put forward as evidence that the heart is not behaving as an equivalent dipole. As our surface voltages were produced by stimulation of a bipolar electrode within the heart, it seems likely that disturbances of the electrical forces in transmission to the body surface are responsible for this pattern. Surface potential patterns of this type do not therefore necessarily indicate that a non-dipolar generator is present. The position of the electrode in this study is probably closer to the chest wall than the equivalent dipole for the natural QRS complex. However, the radiographs show the catheter tip to be deeply situated within the chest, so this error is probably not great. In one patient, Br., the electrode was unusually close to the surface, but the potentials produced in this patient were entirely consistent with a dipolar stimulus. The island of paradoxical potential found in two subjects is just to the right of the anterior mid-line and would particularly affect lead $V_{1}$ of the conventional electrode positions. It seems probable that the low resistivity of the intracardiac blood is responsible for this local distortion of the electrical field. In these circumstances the surface electrocardiogram in this region would be expected to give a distorted impression of cardiac electrical activity.

It is difficult to estimate the location of the equivalent dipole from surface potential maps (Hecht, 1961). Mathematical methods have been proposed (Gabor and Nelson, 1954; Yeh and Martinek, 1957), and some workers (Frank, 1955a; Moore and Langner, 1956) have used QRS mirror cancellation patterns for this purpose. The simple use of the lines of zero and maximum potentials on the body surface is valid only when the dipole is central; this method gave rise to considerable error in the present study. Nelson (1957) using an elliptical laminar model found that the zero potential points were close to the transverse axis of the dipole and that a line joining the maximum and minimum points was roughly parallel to the dipole axis. He suggested the use of the radius to the point on the surface where the potential was changing most rapidly to determine dipole location. In the present work this method generally suggested that the dipole was situated further from the surface of the body than expected from the radiological evidence.

The prediction of the electrode site at an unduly deep position within the thorax using the Nelson (1957) method (Fig. 3) may be accounted for by the distorting effect of the intracardiac blood on the electrical field. The catheter tip was directed to the left and anteriorly in most of these patients 
(Table II) and an area of low resistivity close to the inner pole would be expected to augment the surface potentials in this quadrant (Lepeschkin, 1951). Similar findings could be produced by a region of unusually high resistivity between the electrode and the chest wall, but there is no anatomical feature to create such an effect. In one subject (Br.) both the radiological and the predicted positions of the catheter tip were close to the surface; in this patient the electrode is tangential to the body surface and the cavity blood would not be expected to increase the surface potentials.

Some error in these calculations may be due to the small potential known to be present in the Wilson terminal which will change the apparent position of the zero potential line (Bayley, 1957). Dower, Osborne, and Moore (1959) found an 8 per cent chance of a potential of more than $0.3 \mathrm{mV}$ on this terminal, and in our calculations voltages of less than $0.1 \mathrm{mV}$ have been disregarded because of this error. It seems unlikely that these considerations are contributing in any major way to the failure to locate the dipole accurately in the present study, as the effect of a significant potential at the Wilson terminal will vary with the polarity of the stimulating electrode.

The calculation of apparent resistivity of the thoracic tissues, based on the predicted position of the catheter tip, gives high values in the left anterior chest. These changes are an indication that the predicted electrode position is too far from the surface as a result of the distorting electrical effects of the intracardiac blood. When the radiological position of the electrode is used in the calculation the effect is less evident (Fig. 4). Differences in the relation of the electrodes to the ventricular cavity, which would be expected to have a considerable effect on the electrical field produced by the stimulus (Nelson et al., 1961), probably account for the observed variations in the size of the surface potentials from one patient to another.

The prediction of the orientation of the bipole at the catheter tip gives an estimate of the accuracy of various lead systems and of the way they are affected by disturbances in conductivity of the electrical forces of the heart to the body surface (Burger and van Milaan, 1946, 1947, 1948; Schmitt, 1957). In the present study the orientation of the catheter tip was in general predicted accurately by conventional lead systems in the frontal plane. The use of lead $V_{1}$ as the sagittal component gave poor results for the horizontal plane. The effects of the boundary of the thorax and of variations in electrical conductivity within the thorax do not appear to have a striking effect on any particular limb lead. However, the very considerable individual variations indicate that the conventional electrical axes of these leads cannot be applied to the detailed analysis of the individual electrocardiogram.

\section{CONCLUSIONS AND SUMmaRY}

The electrical field on the surface of the body produced by stimulating a bipolar electrode within the heart has been measured in 5 subjects. In 2 of these patients a complex pattern with more than one region of maximum or minimum potential was obtained. This pattern is usually regarded as evidence of the presence of multiple sources of electrical activity, but was produced in the present study by a single stimulus. Local variations in electrical conductivity within the thorax are probably responsible for the anomalous findings.

In all 5 patients difficulties were encountered in predicting the location of the bipolar electrode from the surface electrocardiogram, and there was considerable variation in the apparent electrical resistivity of the intrathoracic tissues. These findings are further indications of the considerable distortion of electrical forces from the heart in the course of transmission to the body surface. It seems likely that the low resistivity of the blood in the cardiac chambers is the main factor responsible for these disturbances.

This work indicates the insecure basis of much current electrocardiographic and vectorcardiographic theory, and shows the importance of variations in electrical resistivity within the thorax in the interpretation of the effects of cardiac electrical activity at the body surface. Distortion of the electrical field in the præcordial region must produce a disproportionate effect on some conventional electrocardiographic leads. However, the changes produced are not sufficient to interfere seriously 
with the interpretation of limb lead electrocardiograms, though individual variations in the effective axes of these leads must be considerable. care.

We are most grateful to Dr. Wallace Brigden and Dr. Aubrey Leatham for allowing us to study patients under their

\section{REFERENCES}

Bayley, R. H. (1957). Exploratory lead systems and "zero potentials". Ann. N.Y. Acad. Sci., 65, 1110.

Brody, D. A. (1956). A theoretical analysis of intracavitory blood mass influence on the heart-lead relationship. Circulat. Res., 4, 731.

Burch, G. E., Cronvich, J. A., and Zao, Z.Z. (1961). Vectorcardiographic deflections obtained with various reference systems in cadavers. Amer. Heart J., 61, 667.

Burger, H. C., and van Milaan, J. B. (1946). Heart-vector and leads. Brit. Heart J., 8, 157.

- and - (1947). Heart vector and leads. Part II. Brit. Heart J., 9, 154.

-, and - (1948). Heart vector and leads. Part III. Geometrical representation. Brit. Heart J., 10, 229.

,$- \frac{1}{401}$, and den Boer, W. (1952). Comparison of different systems of vectorcardiography. Brit. Heart J., 14,

Butterworth, J. S., and Thorpe, J. J. (1951). On evaluating the Einthoven triangle theory. Circulation, 3, 923.

Craib, W. H., and Canfield, R. (1927). A study of the electrical field surrounding active heart muscle. Heart, 14, 71.

Davies, J. G., and Sowton, G. E. (1964). Cardiac pacemakers. Phys. in Med. Biol., 9, 257.

Dower, G. E., Osborne, J. A., and Moore, A. D. (1959). Measurement of the error in Wilson's central terminal: An accurate definition of unipolar leads. Brit. Heart J., 21, 352.

Einthoven, W., Fahr, G., and de Waart, A. (1913). Über die Richtung und die manifeste Grösse der Potentialschwankungen im menschlichen Herzen und über den Einfluss der Herzlage auf die Form des Elektrokardiogramms. Pflügers Arch. ges. Physiol., 150, 275.

Frank, E. (1955a). Determination of the electrical center of ventricular depolarization in the human heart. Amer. Heart J., 49, 670.

- (1955b). Esophageal dipole design. J. appl. Physiol., 8, 305.

Gabor, D., and Nelson, C. V. (1954). Determination of the resultant dipole of the heart from measurements on the body surface. J. appl. Phys., $25,413$.

Goldberger, E. (1953). Unipolar Lead Electrocardiography and Vectorcardiography, 3rd ed. Lea and Febiger, Philadelphia.

Grishman, A., Borun, E. R., and Jaffe, H. L. (1951). Spatial vectorcardiography. Amer. Heart J., 41, 483.

Hecht, H. H. (1961). Some observations and theories concerning the electrical behavior of heart muscle. Amer. J. Med., 30, 720.

Horan, L. G., Flowers, N. C., and Brody, D. A. (1963). Body surface potential distribution: comparison of naturally and artificially produced signals as analyzed by digital computer. Circulat. Res., 13, 373.

Lepeschkin, E. (1951). Modern Electrocardiography. Williams and Wilkins, Baltimore.

McFee, R., and Johnston, F. D. (1953). Electrocardiographic leads. I. Introduction. Circulation, 8, 554.

, and - (1954a). Electrocardiographic leads. II. Analysis. Circulation, 9, 255.

$\longrightarrow$, and $-(1954 \mathrm{~b})$. Electrocardiographic leads. III. Synthesis. Circulation, 9, 868.

Moore, S. R., and Langner, P. H. (1956). Location of the electrical center of ventricular depolarization. Amer. Heart J., 51, 405.

Nelson, C. V. (1955). Effect of the finite boundary on potential distributions in volume conductors. Circulat. Res., 3, 236.

- (1957). Human thorax potentials. Ann. N.Y. Acad. Sci., 65, 1014.

- (1961). A convenient expression for the potential at the surface of a sphere due to an eccentric dipole. Digest of the 1961 International Conference on Medical Electronics, New York, p. 238.

-, Chatterjee, M., Angelakos, E. T., and Hecht, H. H. (1961). Model studies on the effect of the intracardiac blood on the electrocardiogram. Amer. Heart J., 62, 83.

Rush, S., Abildskov, J. A., and McFee, R. (1963). Resistivity of body tissues at low frequencies. Circulat. Res., $12,40$.

Schmitt, O. H. (1957). Lead vectors and transfer impedance. Ann. N.Y. Acad. Sci., 65, 1092.

Schwan, H. P., and Kay, C. F. (1957). The conductivity of living tissues. Ann. N.Y. Acad. Sci., 65, 1007.

Sowton, E., and Davies, J. G. (1964). Investigation of failure of artificial pacing. Brit. med. J., 1, 1470.

Taccardi, B. (1963). Distribution of heart potentials on the thoracic surface of normal human subjects. Circulat. Res., 12, 341 .

Wilson, F. N., Johnston, F. D., Rosenbaum, F. F., Erlanger, H., Kossmann, C. E., Hecht, H., Cotrim, N., de Oliveira, R. M., Scarsi, R., and Barker, P. S. (1944). The precordial electrocardiogram. Amer. Heart J., $27,19$.

Yeh, G. C. K., and Martinek, J. (1957). Comparisons of surface potentials due to several singularity representations of the human heart. Bull. math. Biophys., 19, 293. 